\title{
Pulchinenosides from Pulsatilla Chinensis Increase P-Glycoprotein Activity and Induce P-Glycoprotein Expression
}

\author{
Yali Liu $\mathbb{D}^{1,2}$ Ling Zhang, ${ }^{1}$ Shaofeng Wei, ${ }^{2}$ Jinyang Cai, ${ }^{3}$ Zhenzhong Zang, ${ }^{1}$ Meng Wang, \\ Dan Su $\left(\mathbb{D},{ }^{1}\right.$ and Phillip M. Gerk $\mathbb{1}^{3}$ \\ ${ }^{1}$ Jiangxi University of Traditional Chinese Medicine, 818 Meiling Road, Nanchang 330006, China \\ ${ }^{2}$ Science and Technology College, Jiangxi University of Traditional Chinese Medicine, 818 Meiling Road, Nanchang 330006, China \\ ${ }^{3}$ Virginia Commonwealth University, MCV Campus, 410 N. 12th Street, Richmond, VA 23298-0533, USA
}

Correspondence should be addressed to Dan Su; sud94@aliyun.com and Phillip M. Gerk; pmgerk@vcu.edu

Received 2 October 2019; Revised 5 December 2019; Accepted 21 December 2019; Published 19 February 2020

Academic Editor: Sebastian Granica

Copyright (C) 2020 Yali Liu et al. This is an open access article distributed under the Creative Commons Attribution License, which permits unrestricted use, distribution, and reproduction in any medium, provided the original work is properly cited.

Five pulchinenosides (pulchinenoside B3, pulchinenoside BD, pulchinenoside B7, pulchinenoside B10, and pulchinenoside B11) isolated from Pulsatilla chinensis (Bge) Regel saponins extract exhibited strong antitumor activities but poor gastrointestinal absorption properties. The enteric induction of P-glycoprotein (P-gp) is understood to restrict the oral bioavailability of some pharmaceutical compounds and lead to adverse drug reactions. Therefore, the present investigation was intended to delineate the impacts of pulchinenosides on cellular P-gp function and expression using Sf9 membrane vesicles and LS180 cells as a surrogate of human intestinal epithelial cells. Preliminary cytotoxic studies showed that $10 \mu \mathrm{M}$ was an acceptable concentration for cytotoxicity and antiproliferation studies for all pulchinenosides using the alamarBlue assay. The cell cycle of LS180 cells detected by flow cytometry was not significantly influenced after 48 hours of coincubation with $10 \mu \mathrm{M}$ of pulchinenosides. In the presence of pulchinenosides, the ATP-dependent transport of N-methyl-quinidine mediated by P-glycoprotein was stimulated significantly. The upregulation of P-glycoprotein and mRNA levels was found by Western blot and real-time PCR analysis in LS180 cells. Parallel changes indicate that all pulchinenosides are exposed to pulchinenosides-mediated transcriptional regulation. In conclusion, pulchinenosides could induce P-glycoprotein expression and directly increase its functional activity.

\section{Introduction}

A febrifugal traditional Chinese medicine named Pulsatilla chinensis (Bge) Regel has been used in medicinal and traditional practices in China and other Eastern countries for centuries. There are 13 Chinese patent medicine formulas and 49 ancient prescriptions containing Pulsatilla chinensis retrieved on the Database of Drug Intelligence NetworkTraditional Chinese medicine prescription [1]. It has been already recorded in the Chinese Pharmacopeia for ages and portrayed as "heat-clearing and detoxification, blood-cooling, and diarrhea-preventing [2]." P. chinensis has been extensively utilized to treat amoebic ailments, vaginal trichomoniasis, microbial diseases, and bacillosis [3]. Now, more and more attention is being paid to its antitumor activities [4-7].
As previously reported, Pulsatilla chinensis saponins (PRS) extract was considered to possess biologically active components that exert potential antitumor activity in nude mice without producing toxicity [8]. Some constituents of Pulsatilla were identified and isolated in ceaseless efforts to find potential biologically active constituents from the Pulsatilla chinensis saponin extract. It was determined that five oleracea pulchinenosides (pulchinenoside B3, pulchinenoside $\mathrm{BD}$, pulchinenoside $\mathrm{B}$, pulchinenoside $\mathrm{B} 10$, and pulchinenoside B11) were major saponins present in the saponin extract [7]. In contrast to anemoside B4, which was described in Chinese Pharmacopeia [2], recent reports revealed that these five pulchinenosides probably explain the antitumor activity of PRS more effectively [9].

These five pulchinenosides are pentacyclic triterpenoids (Figure 1). They are all classified as monodesmosidic 


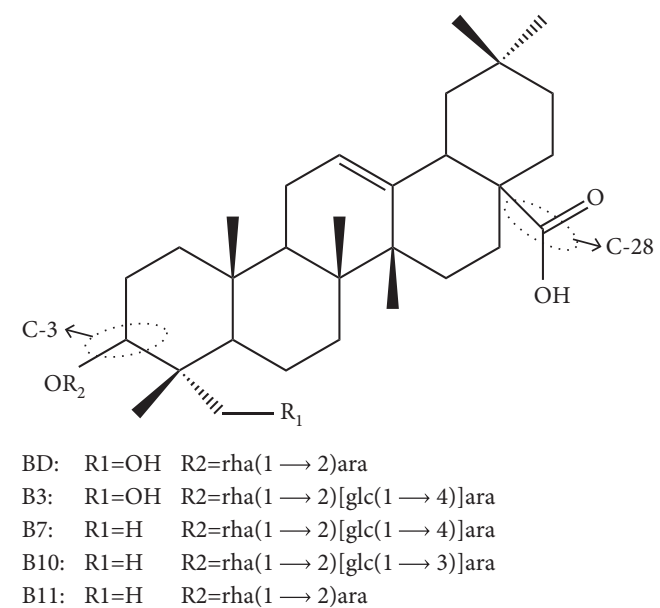

Figure 1: Chemical structures of pulchinenosides.

depending on the quantity of sugar chain presence [10]. They are sorted into hederagenin saponins (pulchinenosides $\mathrm{B} 3$ and $\mathrm{BD}$ ) and oleanolic acid saponins (pulchinenosides B7, B10, and B11) depending on types of sapogenin. The structure-activity relationship of two oleanolic saponins has been explored, and it has been shown that the anticancer activity is related to the 28carboxylic acid and the glycosidic linkage on C-3 [11]. In this study, all five pulchinenosides (pulchinenoside B3, pulchinenoside $\mathrm{BD}$, pulchinenoside $\mathrm{B} 7$, pulchinenoside $\mathrm{B} 10$, and pulchinenoside B11) researched include these dynamic structural characteristics.

Interestingly, our previous research found that the bioavailability of these pulchinenosides $\mathrm{B} 3, \mathrm{BD}, \mathrm{B} 7, \mathrm{~B} 10$, and $\mathrm{B} 11$ in rats was only $1.16 \%, 1.17 \%, 0.55 \%, 0.96 \%$, and $2.50 \%$, respectively, thus exhibiting poor gastrointestinal absorption [12]. Despite extremely low bioavailability, they inhibited the liver tumour growth up to $60 \%$ ex vivo and in vivo [7]. These results suggested that the gastrointestinal absorption barrier, which is probably the main factor limiting its maximum pharmacodynamic effect, cannot be ignored.

A transmembrane protein called P-glycoprotein is a part of the ATP-binding cassette $(\mathrm{ABC})$ transporter superfamily and pumps various chemical substances, including drugs, xenobiotics, natural substances, insecticides, and peptides, out of many cell types using the energy from hydrolysis of ATP $[13,14]$. P-glycoprotein contributes to low and variable oral bioavailability or tissue distribution of its substrates [15]. P-glycoprotein is extensively expressed in the apical membranes of several epithelial tissues necessary for xenobiotic disposition, including intestine, liver, and kidney, as well as the blood-brain barrier $[16,17]$.

The P-glycoprotein expression or function may be induced by some compounds, which then affect the absorption and bioavailability of P-gp substrates themselves. Examples include Chinese patent medicine Siwu decoction [18], Radix Glycyrrhizae and its main components [19], and many other bioactive natural products [13]. In the light of herb-drug interaction, the herbal treatment Saint John's wort which induces both P-gp and CYP3A4 expression, resulting in a decrease in the concentration of cyclosporin in blood and transport rejection in some cases $[20,21]$.

Recently, our research has identified pulchinenosides as substrates of P-glycoprotein in rat intestinal segments [22]. Since this suggested a crucial relationship in low drug bioavailability and P-glycoprotein function, herein, we explore the impacts of pulchinenosides on P-glycoprotein function, which could restrict their absorption. Also, since certain P-glycoprotein function regulators may affect its expression, it is vital to determine the impact of pulchinenosides on P-glycoprotein function and their effect on P-glycoprotein expression. The purpose of this research was to describe the impact of pulchinenosides on the functional activity and expression of P-glycoprotein in LS180 cells and P-glycoprotein overexpressing $S f 9$ insect cell membrane vesicles as a substitute for human intestinal epithelial cells.

\section{Materials and Methods}

2.1. Materials. The passage 38 LS180 cells were purchased from ATCC (Manassas, VA, USA). The materials such as Dulbecco's minimal essential medium (DMEM), fetal bovine serum (FBS), nonessential amino acids (NEAA), and optimum minimal culture medium were from Gibco BRL Life Technologies (Grand Island, New York, USA). Cell culture vessels were from NUNC (Rochester, New York, USA). SuperSignal West Pico enhanced chemiluminescence was purchased from Pierce Incorporation (Rockford, Illinois, USA). Sodium lauryl sulfate and 2-mercaptoethanol were from Merck (Darmstadt, Germany). Sf9 membrane vesicles containing or lacking recombinant human P-gp were from Corning Incorporation (Corning, NY, USA). Polyvinylidene fluoride membranes were from Millipore Corporation (Billerica, Massachusetts, USA). Protein determination dye reagent, tetrabromophenol blue, dithiothreitol, acrylamide/dual solution, and polyethylene glycol octyl phenyl ether were all from Bio-Rad Laboratories Incorporation (Hercules, CA, USA). The antibody used for MDR-1 (sc-13131) and tubulin (sc-398103) was purchased from Santa Cruz Biotechnology Incorporation (Dallas, Texas, USA). Dimethyl sulfoxide, streptomycin sulfate, Hank's balanced salt solution, HEPES, albumin bovine, digoxin, Kodak film, resorufin, and EDTA were all purchased from Sigma-Aldrich Corporation (Saint Louis, Missouri, USA). Resazurin (which gets metabolized to resorufin in the alamarBlue assay) was purchased from Acros Organics (Fair Lawn, NJ, USA). The RNeasy mini kit for extracting RNA was from Bioline (London, UK).

The presented standard five pulchinenosides (pulchinenoside $\mathrm{B} 3$, pulchinenoside $\mathrm{BD}$, pulchinenoside $\mathrm{B} 7$, pulchinenoside B10, and pulchinenoside B11) and hederagenin (purity $>95 \%$ ) were separated in the Department of Natural Medicine (NPEC, Nanchang, People's Republic of China). They were identified by spectral analytical means, containing the optical spectroscopy of MS, ${ }^{1} \mathrm{H}-\mathrm{NMR}$, and ${ }^{13} \mathrm{C}-\mathrm{NMR}$. The information conforms to those documented in the literature $[23,24]$.

$2.5 \mathrm{~kg}$ of the desiccated plant material was extracted three times with $70 \% \mathrm{EtOH}$ and $30 \%$ of water beneath the 
reflux condition. The extractives were then dried under reduced pressure. $280 \mathrm{~g}$ of residue was utilized for performing chromatography using a D101 cationic column, and the elution used a water-EtOH gradient. Fractions were eluted with $60 \% \mathrm{EtOH}$, combined, freeze-dried, and it gained $125 \mathrm{~g}$ of PRS powder [12]. These components (BD, B3, B7, B10, and B11) in PRS extracts were analyzed on HPLC and found to be $24.1 \%, 7.4 \%, 12.4 \%, 13.5 \%$, and $8.5 \%$, respectively, representing $65.9 \%$ of absolute saponins.

2.2. Cell Culture. The passage 52-60 of LS180 cells were cultivated in $15 \mathrm{~mL}$ of DMEM (containing $10 \%$ fetal bovine serum and $1 \%$ nonessential amino acids) in $75 \mathrm{~cm}^{2}$ of cell culture vessels. These cells were grown at $37^{\circ} \mathrm{C}$ with $5 \%$ carbon dioxide and $95 \%$ atmosphere in a carbon dioxide incubator, and the medium was changed every second day until these cells achieve $80-90 \%$ confluence, generally in three to four days. Cells were passaged in the absence of trypsin by scraping then passing 6 cycles through a $23 \mathrm{G} \times 1$ needle.

2.3. Cytotoxicity and Antiproliferation. The alamarBlue assay quantifies the mitochondrial activity of living cells through the reduction of resazurin to resorufin [25]. This assay was applied to determine the cytotoxic and antiproliferative effects of pulchinenosides on LS180 cells. For cytotoxicity research, in brief, LS180 cells were cultivated in the 96-well plates for $48 \mathrm{~h}$ (seeding density: $10^{4}$ cells/well). Solutions of pulchinenosides in DMSO were diluted with DMEM to get concentrations of $0-100 \mu \mathrm{M}$ pulchinenosides and maintained a constant $0.5 \%$ DMSO. Control specimens contained $0.5 \%$ of DMSO in DMEM and $0.1 \%$ of sodium lauryl sulfate in DMEM. The experiment was started by substituting the culture medium in each well with $100 \mu \mathrm{L}$ of control solution or treatment medium and incubating the cells for $4 \mathrm{~h}$ at $37^{\circ} \mathrm{C}$ in a $5 \%$ carbon dioxide incubator. Resazurin $(220 \mu \mathrm{M})$ was added by a Synergy 2 microplate reader (Bio-Tek; Winooski, $\mathrm{VT}$ ) in an amount equivalent to $10 \%$ of the cultivated volume, and the plate was shaken and warmed for $2 \mathrm{~min}$ to start the reaction. Resorufin fluorescence was measured over $10 \mathrm{~min}$ at excitation $530 \mathrm{~nm}$ and emission $590 \mathrm{~nm}$, and slopes were determined using Gen5 software (Bio-Tek). Cellular viability was calculated as the ratio of the slopes for the cells treated with pulchinenosides versus control (no pulchinenosides).

For antiproliferative effects, LS180 cells were plated and allowed to attach on the 96-well plates for $48 \mathrm{~h}$. Next, the medium in every well was replaced with media containing $0-100 \mu \mathrm{M}$ pulchinenosides. The cell plate was incubated for an additional $24 \mathrm{~h}$, and the alamarBlue assay was performed as described above.

2.4. Cell Cycle. LS180 cells $\left(5 \times 10^{5}\right.$ cells/well) were plated on 6-well plates and cultivated for $24 \mathrm{~h}$ in the carbon dioxide incubator with $2 \mathrm{~mL}$ of DMEM medium. This medium was replaced with medium containing $10 \mu \mathrm{M}$ of pulchinenosides and incubated for an additional 24 to $48 \mathrm{~h}$. Attached cells were trypsinized, washed with cold phosphate buffer saline, followed by $75 \% \mathrm{EtOH}$, and stored at $-20^{\circ} \mathrm{C}$. Cells were rinsed again with phosphate-buffered saline before staining (ribonuclease A: $200 \mathrm{mg} / \mathrm{mL}$, propidium iodide (PI), Triton $\mathrm{X}-100$ in phosphate buffer saline: $0.1 \%)$. The analysis of cells on the flow cytometry instrument (Guava Technologies Inc., California, USA) was performed via the FITC channel, and $5 \times 10^{3}$ cells were collected each time.

2.5. Transport Study. The Sf9 membrane vesicle assay has been adopted for a transport study [26, 27]. In brief, $S f 9$ insect cell membrane vesicles lacking (control) or overexpressing human P-glycoprotein were obtained from Optivia Biotechnology (Santa Clara, CA). The complete buffer contained $5 \mathrm{mM}$ adenosine triphosphate (ATP) or adenosine monophosphate (AMP), creatine phosphokinase $(100 \mu \mathrm{g} / \mathrm{mL})$, creatine phosphate $(10 \mathrm{mM})$, Tris $\mathrm{HCl}(10 \mathrm{mM})$ at $\mathrm{pH} 7.4$, sucrose $(250 \mathrm{mM}), \mathrm{MgCl}_{2}(10 \mathrm{mM})$, N-methylquinidine (final concentration $10 \mu \mathrm{M}$ ), and $10 \mu \mathrm{M}$ pulchinenosides in DMSO (concentration up to $0.5 \% \mathrm{v} / \mathrm{v}$ ). The prewarmed solutions were mixed with P-glycoprotein or control membrane vesicles (final concentration $0.5 \mu \mathrm{g} / \mathrm{mL}$ ) and incubated at $37^{\circ} \mathrm{C}$ for $5 \mathrm{~min}$ and then transferred to a Millipore Multiscreen filter plate (Millipore: MAHVN4510, Milford, MA). Each well was aspirated and then rinsed three times with iced buffer, including $10 \mathrm{mM}$ Tris HCL in pH 7.4, $250 \mathrm{mM}$ sucrose, and $100 \mathrm{mM}$ sodium chloride. N-methylquinidine was eluted from the filters with $92 \% \mathrm{ACN}$ and $8 \%$ water.

Quantification of N-methyl-quinidine [28] was performed on a Waters 2695 HPLC system (Waters Technologies Inc., Massachusetts, USA) with a Waters 2475 fluorescence detector (excitation wavelength $330 \mathrm{~nm}$ and excitation wavelength $400 \mathrm{~nm}$ ), using Phenomenex $\mathrm{C}_{18}$ column $(4.6 \times 150 \mathrm{~mm}, 3 \mu \mathrm{m})$. The HPLC method comprised an isocratic mobile phase flow $(1 \mathrm{~mL} / \mathrm{min})$ of $75 \%$ methanol and $25 \%$ aqueous ( $0.5 \%$ formic acid and $0.1 \%$ triethylamine). Nonspecific binding of N-methyl-quinidine was corrected by subtracting the values in the absence of ATP (substituted with AMP), and $S f 9$ endogenous transport activity was corrected by subtracting the control membrane values, thus yielding values for ATP-dependent and P-glycoproteinmediated transport activity.

The assay for pulchinenosides in rat plasma was validated following the guidance for the bioanalytical methods validation [29].

2.6. Western Blot Analysis of P-gp. After treatment, the LS180 cells were harvested, and whole-cell pellets were lysed by sonication in $1 \mathrm{x}$ sample buffer $(200 \mathrm{mM}$ Tris- $\mathrm{HCl}$ at $\mathrm{pH} 6.8$, $2 \%$ sodium dodecyl sulfate, $10 \%$ glycerol, $0.2 \%$ bromphenol blue, and proteinase inhibitor cocktail) and boiled for $10 \mathrm{~min}$. Equivalent amounts of protein lysates were placed in $8 \%$ SDS PAGE gels and separated; then, the protein products were electrophoretically transferred to PVDF films (Millipore, Billerica, MA). After incubation for $60 \mathrm{~min}$ with $5 \%$ skims milk in phosphate-buffered saline with Tween-20 (PBST), the film was rinsed once with PBST, and the primary 
antibody was gently rocked overnight at $4^{\circ} \mathrm{C}$. Membranes were then rinsed 3 times for $5 \mathrm{~min}$ and hatched with antirabbit or HRP-conjugated anti-mouse antibody diluted $1: 5000$ at room temperature for $1 \mathrm{~h}$. The blot was rinsed in PBST 3 times and developed by an ECL system (Pierce, ThermoFisher). The blot was performed 3 times, and densitometry was quantitated using NIH ImageJ software.

2.7. Real-Time RT-PCR Analysis of ABCB1 mRNA. Total RNA was extracted from LS180 cells using the ISOLATE RNA mini kit (Bioline, cat. no. BIO-52072). $1 \mu \mathrm{g}$ of total RNA was applied to cDNA reverse transcription using a kit (Applied Biosystems, cat. no. 4368814). The SYBR Green main mixtures (Applied Biosystems, cat. no. A25742) were applied to real-time PCR, and the results were analyzed using QUANT-STUDIO 3.0 software. ABCB1 mRNA abundance was standardized to the expression of glyceraldehyde-phosphate dehydrogenase (GAPDH). The primers applied to PCR are as follows:

$$
\begin{aligned}
& 5^{\prime} \text {-CTGCTTGATGGCAAAGAAATAAAG-3' (forward) } \\
& \text { and } \\
& 5^{\prime} \text {-GGCTGTTGTCTCCATAGGCAAT-3' (reverse) for } \\
& \text { MDR-1 and } \\
& 5^{\prime} \text {-AATCCCATCACCATCTTCCA-3' (forward) and } \\
& 5^{\prime} \text {-TGGACTCCACGACGTACTCA-3' (reverse) for } \\
& \text { GAPDH. }
\end{aligned}
$$

2.8. Statistical Analyses. Data were plotted as average value \pm SD applying GraphPad Prism 7.00 (GraphPad Software Incorporation, La Jolla, California, USA). One way ANOVA (Dunnett's) postanalysis and two way ANOVA (Bonferroni's) postanalysis were used for comparisons $\left({ }^{*} P<0.05\right)$. Nonlinear regression (Prism) was used to determine $\mathrm{IC}_{50}$ values.

\section{Results}

3.1. Cytotoxicity and Antiproliferative Activity. After $4 \mathrm{~h}$ exposure to pulchinenosides (up to $100 \mu \mathrm{M}$ ), significant toxicity was observed at concentrations of $100 \mu \mathrm{M}$ for B3, $\mathrm{BD}$, and PRS and $30 \mu \mathrm{M}$ for B7, B10, and B11 (Figure 2). The proliferation of LS180 cells was also dependent upon pulchinenosides concentrations. Although cell proliferation was not affected by pulchinenosides at $1 \mu \mathrm{M}$ for $\mathrm{B} 3$ and $\mathrm{BD}$ and $3 \mu \mathrm{M}$ for $\mathrm{B} 7, \mathrm{~B} 10, \mathrm{~B} 11$, and PRS, cell viability was affected significantly at $3 \mu \mathrm{M}$ for $\mathrm{B} 3$ and $\mathrm{BD}$ and at $10 \mu \mathrm{M}$ for $\mathrm{B} 7, \mathrm{~B} 10$, $\mathrm{B} 11$, and PRS, respectively. $\mathrm{IC}_{50}$ values for $\mathrm{B} 3, \mathrm{BD}, \mathrm{B} 7, \mathrm{~B} 10$, $B 1$, and PRS were $4.13 \pm 0.45,7.05 \pm 0.52,5.77 \pm 0.36$, $7.49 \pm 0.46,8.78 \pm 0.68,9.78 \pm 0.27 \mu \mathrm{M}$, respectively. Therefore, for all these compounds, $10 \mu \mathrm{M}$ was chosen to evaluate the effects of the compounds on the cell cycle (Figure 3).

3.2. Cell Cycle. The cell cycle progression, however, was relevant with a substantial change in proliferation rate, as shown in (Figures 4 and 5). After $48 \mathrm{~h}$ of exposure to $10 \mu \mathrm{M}$

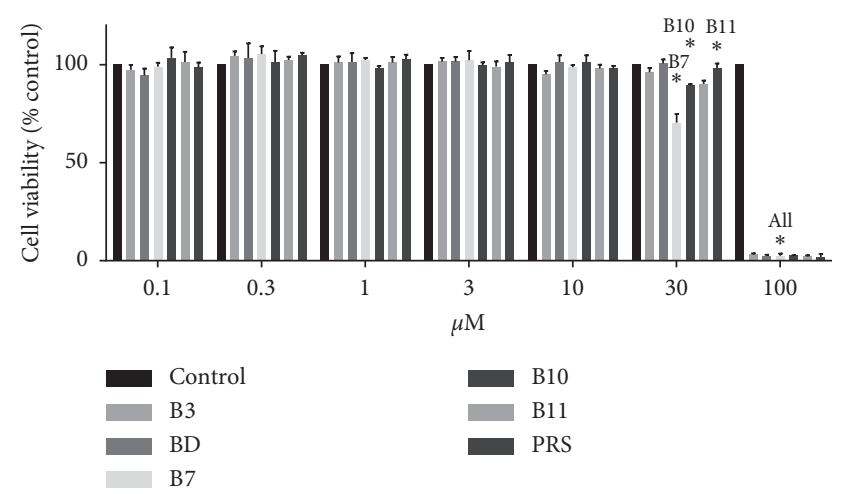

FIGURE 2: Effect of different concentrations of pulchinenosides on the viability of LS180 cells as assessed by alamarBlue assay after 4 hours of incubation $(n=3$, mean $\pm \mathrm{SD}) .{ }^{*} P<0.05$.

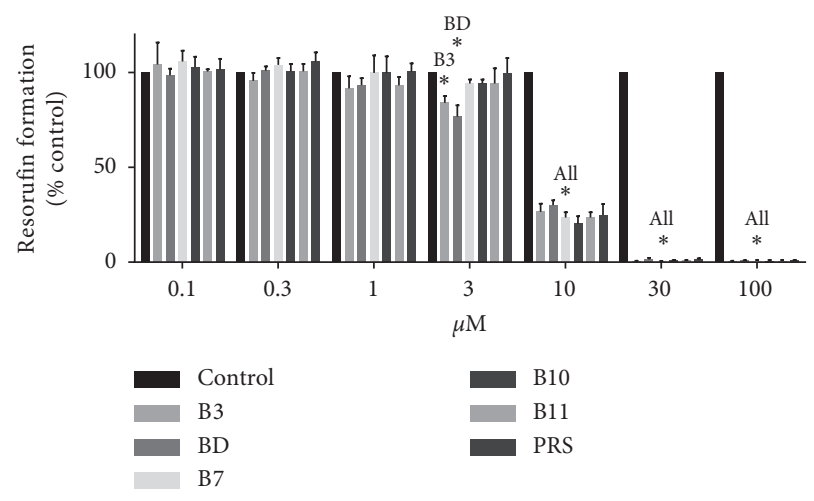

FIGURE 3: Effects of different concentrations of pulchinenosides on the proliferation of LS180 cells as assessed by alamarBlue assay after 72 hours of incubation $(n=3$, mean $\pm \mathrm{SD})$. ${ }^{*} P<0.05$.

pulchinenosides, there was no significant effect on cycle distribution.

3.3. Transport Study. Transport studies showed that the ATP-dependent, P-glycoprotein-mediated accumulation of $\mathrm{N}$-methyl-quinidine (NMQ) in the inside-out membrane vesicles increased significantly in the presence of $10 \mu \mathrm{M}$ concentrations of B3, B7, B11 and PRS as shown in (Figure 6). These results indicate that $10 \mu \mathrm{M}$ stimulated the transport of $\mathrm{N}$-methyl-quinidine by $\mathrm{P}$-glycoprotein pulchinenosides nearly two-fold for B11 and PRS.

3.4. P-Glycoprotein Expression. Western Blot determined P-glycoprotein expression in the LS180 cells plated on the 6well plate. On day 9, cells were exposed to $10 \mu \mathrm{M}$ of various pulchinenosides for $48 \mathrm{~h}$. As indicated in (Figure 7), all pulchinenosides significantly upregulated the membrane expression level of P-glycoprotein in cells.

3.5. ABCB1 mRNA Expression. ABCB1 mRNA in the LS180 cells cultivated on the 6-well plate was quantified, applying real-time RT-PCR analysis standardized to the blank control. It suggested that all the pulchinenosides, regardless of 

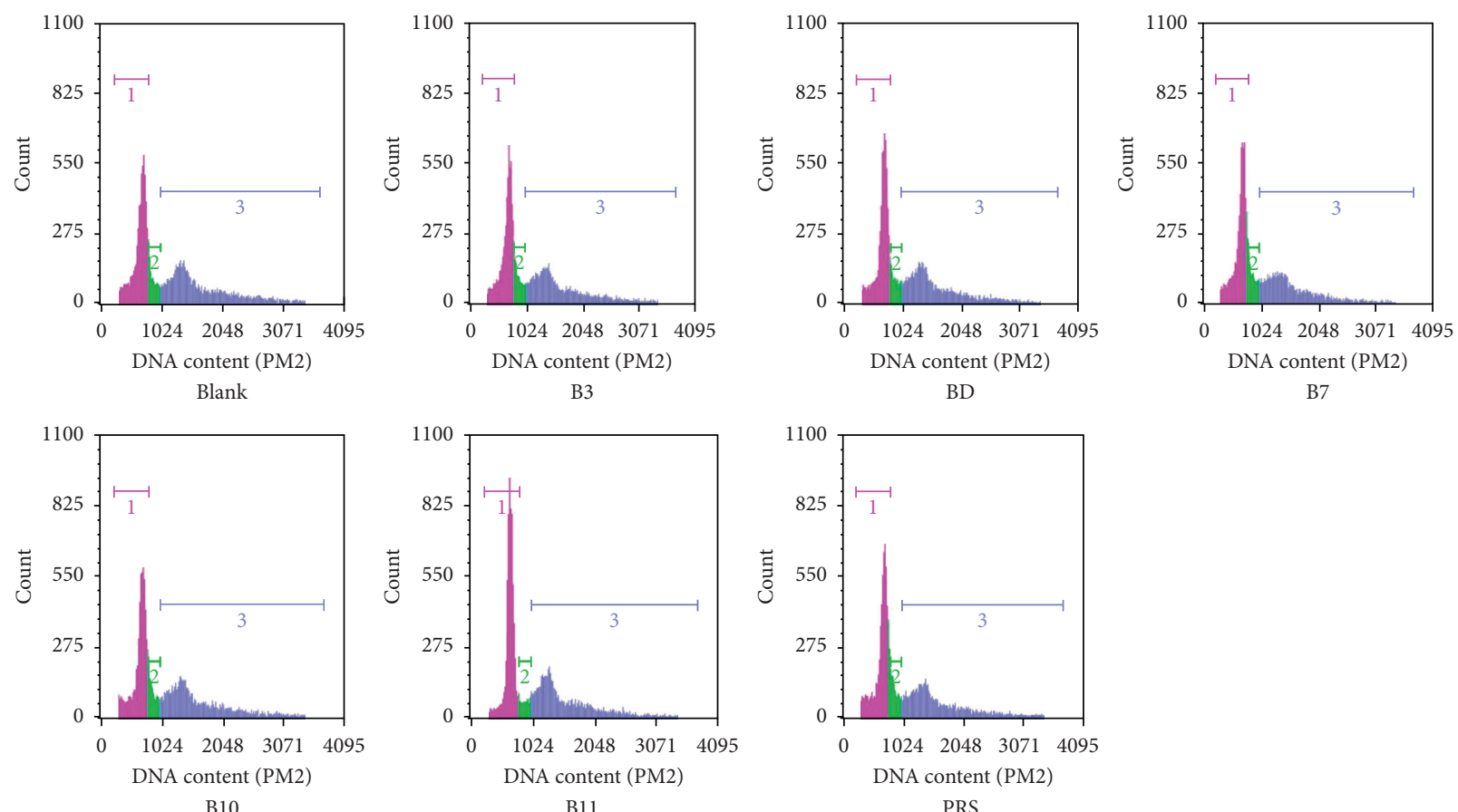

FIGURE 4: DNA content of cell cycle distributed on LS180 cells cocultivated with pulchinenosides $(10 \mu \mathrm{M})$ for 48 hours. Blank is the negative control; B3, BD, B7, B10, B11, and PRS represent pulchinenosides as described.

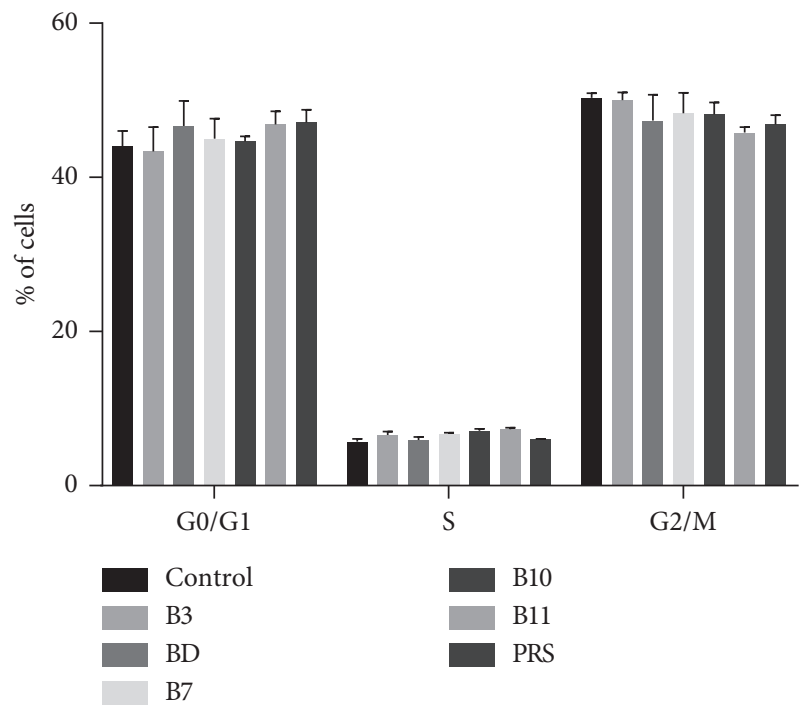

FIGURE 5: Cell cycle distributed on LS180 cells cultivated with pulchinenosides for 48 hours $(n=3$, mean $\pm \mathrm{SD}) .{ }^{*} P<0.05$.

the type of saponin, upregulated the ABCB1 mRNA expression on LS180 cells (Figure 8), and all pulchinenosides have significant differences, especially for B3, B10, B11, and PRS, which induced ABCB1 mRNA transcription more than 2 -fold that of control. These results suggested a pulchinenosides-mediated transcriptional modulation.

\section{Discussion}

Intestinal P-gp plays a crucial role in the absorption and excretion of oral xenobiotics and drugs. The changes in

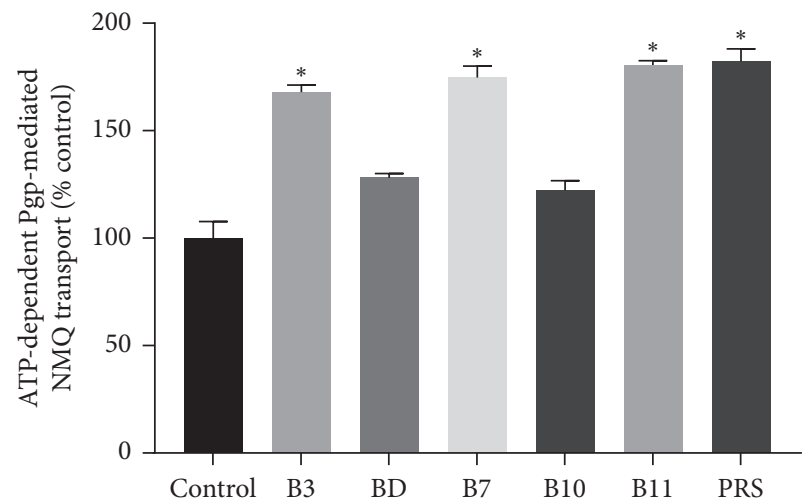

FIGURE 6: The effects of pulchinenosides $(10 \mu \mathrm{M})$ on P-glycoprotein transport activity $(n=3$, mean $\pm \mathrm{SD}) .{ }^{*} P<0.05$.

P-glycoprotein/ABCB1 activity due to its induction and/or inhibition will lead to drug-drug or herbal-drug interaction that can change pharmacodynamics and drug response $[30,31]$. Thus, compounds which affect the functional activity and expression of P-gp are vital from the pharmaceutical and toxicological perspective [32]. Within this research, we assessed the effects of pulchinenosides exposure on P-glycoprotein function in $S f 9$ membrane vesicles and expression in LS180 cells. To our knowledge, this is the first report to examine the influence of pulchinenosides, an anticancer traditional Chinese herbal drug, on both the P-gp transport activity and expression in LS180 human intestinal cells.

In bioavailability research, a chemical compound is usually administered orally or intravenously, which is the primary method for deciding the definite bioavailability value of a single chemical drug [26]. While keeping in mind 

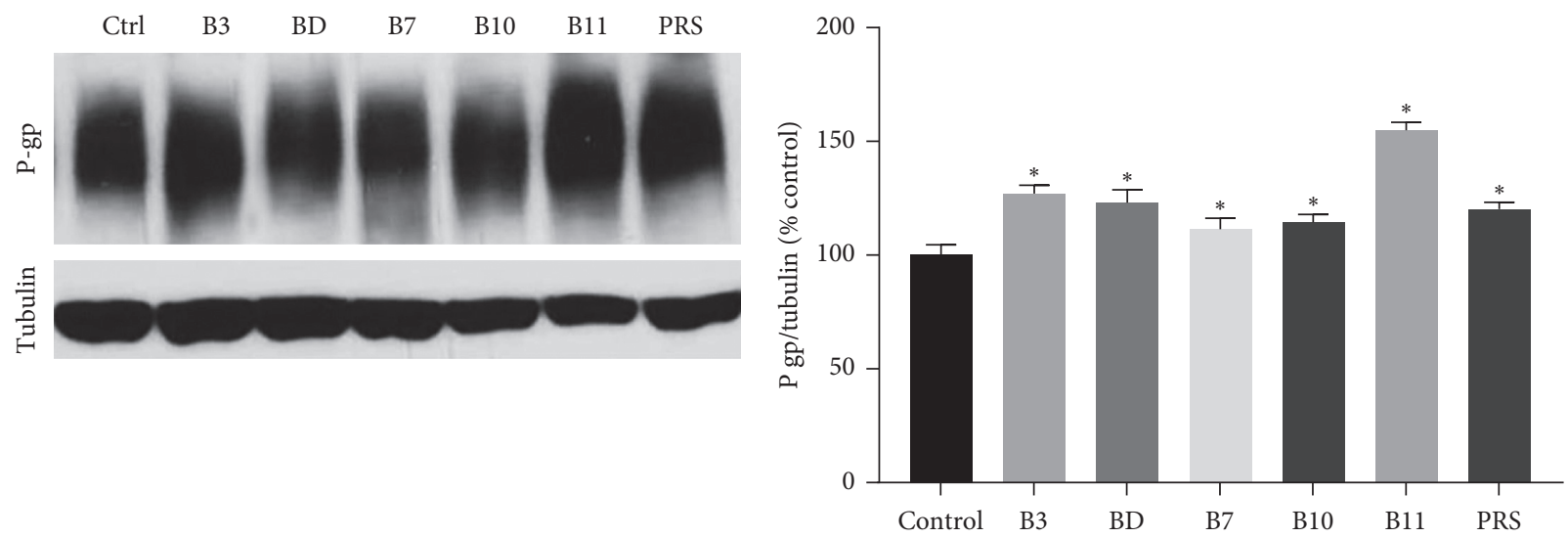

(a)

(b)

FIGURE 7: P-glycoprotein expression levels were cultivated in 6-well plates and exposed to $10 \mu \mathrm{M}$ pulchinenosides for 48 hours on LS180 cells. (a) Representative western blots of P-gp and tubulin. (b) Densitometry scans of western blots $\left(n=3\right.$, mean \pm SD). ${ }^{*} P<0.05$.

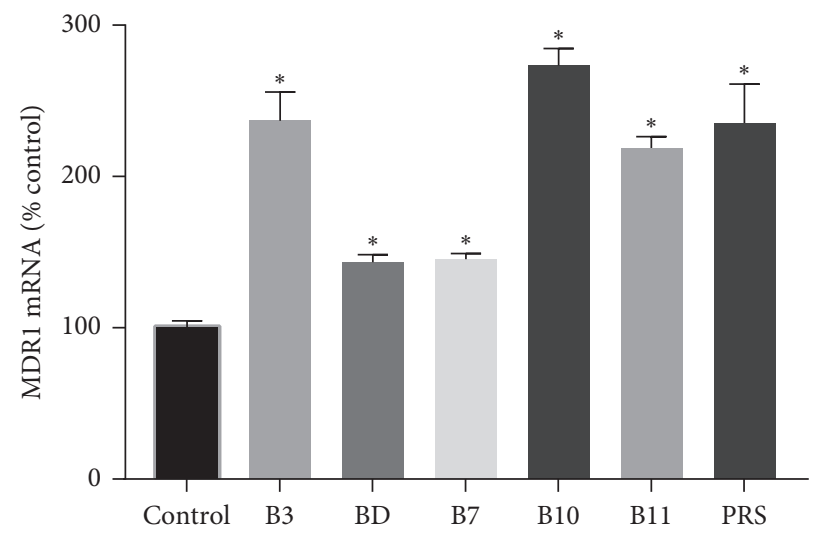

FIGURE 8: RT-polymerase chain reaction analysis of multidrug resistance gene $1 \mathrm{mRNA}$ in LS180 cells exposed to pulchinenosides for 48 hours $(n=3$, mean $\pm \mathrm{SD}) .{ }^{*} P<0.05$.

the multifaceted nature of TCMs [23], different components may interact. Thus, when estimating their bioavailability or studying the mechanisms involved, it is better to study the compounds in combination(s) as well as individually. That is why, we studied not only purified compounds (B3, BD, B7, $\mathrm{B} 10$, and B11) but also mixed compounds (PRS).

The cytotoxic effects of pulchinenosides were also examined in this project. At $30 \mu \mathrm{M}$ concentrations of $\mathrm{B} 3, \mathrm{BD}$, and PRS and at $10 \mu \mathrm{M}$ of B7, B10, and B11, pulchinenosides did not show cytotoxic effect after $4 \mathrm{~h}$ exposure. Pulchinenosides B3 and $\mathrm{BD}(3 \mu \mathrm{M})$ and $\mathrm{B} 7, \mathrm{~B} 10, \mathrm{~B} 11$, and PRS $(10 \mu \mathrm{M})$ reduced cell proliferation when the exposure cycle was extended to $72 \mathrm{~h}$. Compared with the control group, pulchinenosides did not have a significant influence on cell cycle progression.

The P-gp expression is generally influenced by many in vitro and in vivo factors, which include extracellular matrix, growth factors, arsenite, heat shock, partial hepatectomy, protein kinase C agonists, sodium butyrate, and even some of its inhibitors and substrates [33]. In our study, pulchinenosides apparently stimulated the ABCB1/P-gp transport of N-methyl-quinidine. This result suggests that pulchinenosides may have the potential to reduce the intestinal absorption of P-glycoprotein substrates. There are many drugs that are usually considered P-gp substrates, but they can also upregulate the expression of ABCB1/P-gp [34, 35]. We had previously demonstrated that pulchinenosides were substrates of P-glycoprotein, and their movement across the rat intestinal epithelium was directed by P-glycoprotein-mediated efflux activities [22]. In the present study, we have shown that pulchinenosides (especially, B3, B7, $\mathrm{B} 11$, and PRS) at $10 \mu \mathrm{M}$ concentrations were capable of significantly stimulating P-glycoprotein transport activity. As a result, the enhanced expression and activity of P-glycoprotein could inhibit the absorption of such components and limit their bioavailability [36].

Cells can respond to the existence of xenobiotics via upregulating drug efflux pumps, such as P-gp, to prolong their survival. In terms of the influence of pulchinenosides on P-glycoprotein function, $48 \mathrm{~h}$ exposure to pulchinenosides appeared to consistently increase P-glycoprotein expression in the LS180 cells, although the mechanism has yet to be identified. In contrast to most steroidal saponins [37] that might downregulate $\mathrm{P}$-gp expression, pulchinenosides exposure leads to the upregulation of P-gp/ABCB1 state. Potential mechanisms involved within the induction of $\mathrm{P}$-gp functional activity, and expression could involve the Pregnane $\mathrm{x}$ Receptor (PXR) [38], protein kinase C [39], and the 
initiation of the NF-kB [40] and the PI3-kinase/Akt [41] pathways. PXR activation is among the potential pathways associated with the transcriptional initiation of the ABCB1 expression. Certain compounds such as anticancer drugs, cholesterol-lowering statins, plant extracts, rifampin, and HIV protease inhibitors are among the PXR ligands [42-44]. The dietary phytochemicals tangeretin and gingkolides $\mathrm{A}$ and $\mathrm{B}$ significantly induced expression and activity of P-gp in LS180 cells through PXR [45]. Furthermore, P-gp is also induced by $1 \alpha, 25$-dihydroxy vitamin $\mathrm{D} 3$ through the vitamin-D receptor, meanwhile, also inducing cytochrome $\mathrm{P} 450$ $3 \mathrm{~A} 4$ [46]. Our data showing induction of P-gp expression by pulchinenosides are consistent with these previous studies, although further experiments are needed to determine the regulatory mechanism.

\section{Conclusion}

In summary, this research has indicated that to differing extents, pulchinenosides can stimulate P-glycoprotein functional activities and upregulate P-glycoprotein/ABCB1 mRNA and protein expression. Further research is required to clarify the mechanism of increased P-glycoprotein activity and expression via regulatory pathways. These results suggest that both short-term and long-term dosing of pulchinenosides has the potential to reduce the oral bioavailability of P-glycoprotein substrates.

\section{Abbreviations}

P-gp: P-glycoprotein

Sf9: $\quad$ Spodoptera frugiperda

HPLC: High-performance liquid chromatography

ATP: $\quad$ Adenosine triphosphate

RT-PCR: Reverse transcriptase-polymerase chain reaction ABCB1: Multidrug resistance protein 1.

\section{Data Availability}

The data used to support the findings of this study are available from the corresponding author upon request.

\section{Disclosure}

Professor Yali Liu is a visiting scientist hosted by the VCU Department of Pharmaceutics.

\section{Conflicts of Interest}

The authors declare no conflicts of interest.

\section{Acknowledgments}

This study was supported by grants from the National Sciences Foundation of China (nos. 81603377 and 81460594), the Science and Technology Research Project of Jiangxi Education Department and Jiangxi Health and Family Planning Commission of China (nos. GJJ151565, GJJ181579, and 2015A054), Double First-class Discipline (Chinese materia medica) Construction Project Fund of Jiangxi Province
(JXSYLXK-ZHYAO067, JXSYLXK-ZHYAO069, JXSYLXKZHYAO070, JXSYLXK-ZHYAO106), Natural Science Foundation of Jiangxi Province (20171BAB205092), Excellent Youth Foundation of Jiangxi Scientific Committee (20171BCB23045), Key Research and Development Project of Jiangxi Province (20171BBG70112), and National Institutes of Health (USA) (grant no. R21-EB022206). The authors also acknowledge Palak Phansalkar for helping with culturing LS180 cells.

\section{References}

[1] https://db.yaozh.com/fangji/, China.

[2] CP. Committee, Chinese Pharmacopoeia 2015, China Medical Science and Technology Press, Beijing, China, 2015.

[3] ZH, Modern Study of Traditional Chinese Medicine, Xueyuan Press, Beijing, China, 1997.

[4] Z. Shu, Z. Chen, X.-j. Ding et al., "Three new triterpenoids from Pulsatilla chinensis (bunge) Regel and their cytotoxic activities," Heterocycles, vol. 83, no. 10, pp. 2365-2372, 2011.

[5] W. Hai-Xia, X. Y. Zheng, and J. Gao, "Pulchinenoside B4 inhibits proliferation and induces apoptosis of human liver cancer cell line HepG2 in vitro," Journal of Shanghai Jiaotong university (Medical Science), vol. 31, no. 10, pp. 1481-1485, 2011.

[6] L. Zhang, A. Naeem, S. Wei et al., "PPTS inhibits the TGF- $\beta 1$ induced epithelial-mesenchymal transition in human colorectal cancer SW480 cells," Evidence-Based Complementary and Alternative Medicine, vol. 2019, Article ID 2683534, 2019.

[7] Y. Y. Luo, L. Y. Chen, Y. R. Cui, M. Duan, M. L. Wang, and J. S. Guo, "Inhibition of human HT29 colorectal cancer cell proliferation and apoptosis induction by saponins from Pulsatilla chinensis," Pharmacology and Clinic of Traditional Chinese Medicine, vol. 29, no. 05, pp. 52-56, 2013.

[8] Q.-m. Xu, Z. Shu, W.-j. He et al., "Antitumor activity of Pulsatilla chinensis (bunge) regel saponins in human liver tumor 7402 cells in vitro and in vivo," Phytomedicine, vol. 19, no. 3-4, pp. 293-300, 2012.

[9] W. Y. Xu kun SZ, Q. Xu, S. Yang, and Y. Liu, "Pharmacodynamics of saponin D anti-liver cancer," Chinese Patent Medicine, vol. 36, no. 2, pp. 240-244, 2014.

[10] Ö. Güçlü-Üstündağ and G. Mazza, "Saponins: properties, applications and processing," Critical reviews in food science and nutrition, vol. 47, no. 3, pp. 231-258, 2007.

[11] S.-C. Bang, J.-H. Lee, G.-Y. Song, D.-H. Kim, M.-Y. Yoon, and B.-Z. Ahn, "Antitumor activity of Pulsatilla koreana saponins and their structure-activity relationship," Chemical \& Pharmaceutical Bulletin, vol. 53, no. 11, pp. 1451-1454, 2005.

[12] Y. Liu, Y. Song, Q. Xu et al., "Validated rapid resolution LCESI-MS/MS method for simultaneous determination of five pulchinenosides from Pulsatilla chinensis (bunge) regel in rat plasma: application to pharmacokinetics and bioavailability studies," Journal of Chromatography B, vol. 942-943, pp. 141-150, 2013.

[13] A. H. Abuznait, H. Qosa, N. D. O'Connell et al., "Induction of expression and functional activity of P-glycoprotein efflux transporter by bioactive plant natural products," Food and Chemical Toxicology, vol. 49, no. 11, pp. 2765-2772, 2011.

[14] A. H. Schinkel and J. W. Jonker, "Mammalian drug efflux transporters of the ATP binding cassette (ABC) family: an overview," Advanced Drug Delivery Reviews, vol. 64, pp. 138-153, 2012. 
[15] S. Marchetti, R. Mazzanti, J. H. Beijnen, and J. H. M. Schellens, "Concise review: clinical relevance of drug-drug and herbdrug interactions mediated by the $\mathrm{ABC}$ transporter $\mathrm{ABCB} 1$ (MDR1, P-glycoprotein)," The Oncologist, vol. 12, no. 8, pp. 927-941, 2007.

[16] F. Thiebaut, T. Tsuruo, H. Hamada, M. M. Gottesman, I. Pastan, and M. C. Willingham, "Cellular localization of the multidrug-resistance gene product P-glycoprotein in normal human tissues," Proceedings of the National Academy of Sciences, vol. 84, no. 21, pp. 7735-7738, 1987.

[17] K. Y. Dale, "The contribution of P-glycoprotein to pharmacokinetic drug-drug interactions," The Journal of Clinical Pharmacology, vol. 39, no. 12, pp. 1203-1211, 1999.

[18] Y. Jiang, Z. Ma, X. Huang et al., "Effect of siwu decoction on function and expression of P-glycoprotein in Caco-2 cells," China Journal of Chinese Materia Medica, vol. 40, no. 5, pp. 933-937, 2015.

[19] D. He, M. Yan, H. D. Li et al., "Effects of radix glycyrrhiza and its main components on the function and expression of P-glycoprotein in Caco-2 cells," Chinese Pharmaceutical Journal, vol. 45, no. 10, pp. 751-755, 2010.

[20] F. Ruschitzka, P. J. Meier, M. Turina, T. F. Lüscher, and G. Noll, “Acute heart transplant rejection due to Saint John's wort,” The Lancet, vol. 355, no. 9203, pp. 548-549, 2000.

[21] E. Ernst, "Herb-drug interactions: potentially important but woefully under-researched," European Journal of Clinical Pharmacology, vol. 56, no. 8, pp. 523-524, 2000.

[22] Y. Liu, Y. Song, Z. Guan et al., "Intestinal absorption of pulchinenosides from Pulsatilla chinensis in rats," China Journal of Chinese Materia Medica, vol. 40, no. 3, pp. 543-549, 2015.

[23] R. Yuan and Y. Lin, "Traditional Chinese medicine an approach to scientific proof and clinical validation," Pharmacology \& Therapeutics, vol. 86, no. 2, pp. 191-198, 2000.

[24] Q. W. Zhang, W. C. Ye, C. T. Che, and S. X. Zhao, "Triterpene saponins from Pulsatilla cernua," Acta Pharmaceutica Sinica, vol. 35, no. 10, pp. 756-759, 2000.

[25] S. N. Rampersad, "Multiple applications of alamar blue as an indicator of metabolic function and cellular health in cell viability bioassays," Sensors, vol. 12, no. 9, pp. 12347-12360, 2012.

[26] P. M. Gerk and M. Vore, "Multidrug resistance proteins and hepatic transport of endo-and xenobiotics," in Drug Metabolism and Transport, pp. 273-289, Humana Press, Totowa, NJ, USA, 2005.

[27] L. Huang, T. Hoffman, and M. Vore, "Adenosine triphosphate-dependent transport of estradiol-17 $\beta$ ( $\beta$-d-glucuronide) in membrane vesicles by MDR1 expressed in insect cells," Hepatology, vol. 28, no. 5, pp. 1371-1377, 1998.

[28] Z. Miskolczy, J. G. Harangozó, L. Biczók, V. Wintgens, C. Lorthioir, and C. Amiel, "Effect of torsional isomerization and inclusion complex formation with cucurbit[7]uril on the fluorescence of 6-methoxy-1-methylquinolinium," Photochemical \& Photobiological Sciences, vol. 13, no. 3, pp. 499-508, 2014.

[29] Food and Drug Administration, Guidance for Industry: Bioanalytical Method Validation, FDA, Silver Spring, MD, USA, 2001.

[30] C. G. Dietrich, A. Geier, and R. O. Elferink, "ABC of oral bioavailability: transporters as gatekeepers in the gut," Gut, vol. 52, no. 12, pp. 1788-1795, 2003.

[31] S.-F. Zhou, "Structure, function and regulation of P-glycoprotein and its clinical relevance in drug disposition," Xenobiotica, vol. 38, no. 7-8, pp. 802-832, 2008.

[32] Y. Han, T. M. C. Tan, and L.-Y. Lim, "Effects of capsaicin on P-gp function and expression in Caco-2 cells," Biochemical Pharmacology, vol. 71, no. 12, pp. 1727-1734, 2006.
[33] M. M. Gottesman, C. Hrycyna, P. V. Schoenlein, U. Germann, and I. Pastan, "Genetic analysis of the multidrug transporter," Annual Review of Genetics, vol. 29, no. 1, pp. 607-649, 1994.

[34] E. G. Schuetz, W. T. Beck, and J. D. Schuetz, "Modulators and substrates of P-glycoprotein and cytochrome P4503A coordinately up-regulate these proteins in human colon carcinoma cells," Molecular Pharmacology, vol. 49, no. 2, pp. 311-318, 1996.

[35] P. M. Chaudhary and I. B. Roninson, "Induction of multidrug resistance in human cells by transient exposure to different chemotherapeutic drugs," JNCI Journal of the National Cancer Institute, vol. 85, no. 8, pp. 632-639, 1993.

[36] P. M. Gerk, W. Li, V. Megaraj, and M. Vore, "Human multidrug resistance protein 2 transports the therapeutic bile salt tauroursodeoxycholate," Journal of Pharmacology and Experimental Therapeutics, vol. 320, no. 2, pp. 893-899, 2007.

[37] T. Yan, G. Hu, A. Wang, X. Sun, X. Yu, and J. Jia, "Paris saponin VII induces cell cycle arrest and apoptosis by regulating Akt/MAPK pathway and inhibition of P-glycoprotein in K562/ADR cells," Phytotherapy Research, vol. 32, no. 5, pp. 898-907, 2018.

[38] A. Geick, M. Eichelbaum, and O. Burk, "Nuclear receptor response elements mediate induction of intestinal MDR1 by rifampin," Journal of Biological Chemistry, vol. 276, no. 18, pp. 14581-14587, 2001.

[39] E. Flescher and R. Rotem, "Protein kinase $C \varepsilon$ mediates the induction of P-glycoprotein in LNCaP prostate carcinoma cells," Cellular Signalling, vol. 14, no. 1, pp. 37-43, 2002.

[40] F. Thévenod, J. M. Friedmann, A. D. Katsen, and I. A. Hauser, "Up-regulation of multidrug resistance P-glycoprotein via nuclear factor- $\kappa \mathrm{B}$ activation protects kidney proximal tubule cells from cadmium-and reactive oxygen species-induced apoptosis," Journal of Biological Chemistry, vol. 275, no. 3, pp. 1887-1896, 2000.

[41] O. M. Nwaozuzu, L. A. Sellers, and M. A. Barrand, "Signalling pathways influencing basal and $\mathrm{H}_{2} \mathrm{O}_{2}$-induced P-glycoprotein expression in endothelial cells derived from the blood-brain barrier," Journal of Neurochemistry, vol. 87, no. 4, pp. 10431051, 2004.

[42] J. M. Maglich, C. M. Stoltz, B. Goodwin, D. Hawkins-Brown, J. T. Moore, and S. A. Kliewer, "Nuclear pregnane X receptor and constitutive androstane receptor regulate overlapping but distinct sets of genes involved in xenobiotic detoxification," Molecular Pharmacology, vol. 62, no. 3, pp. 638-646, 2002.

[43] J. M. Rosenfeld, R. Vargas Jr, W. Xie, and R. M. Evans, "Genetic profiling defines the xenobiotic gene network controlled by the nuclear receptor pregnane X receptor," Molecular Endocrinology, vol. 17, no. 7, pp. 1268-1282, 2003.

[44] Y. Chen, Y. Tang, C. Guo, J. Wang, D. Boral, and D. Nie, "Nuclear receptors in the multidrug resistance through the regulation of drug-metabolizing enzymes and drug transporters," Biochemical Pharmacology, vol. 83, no. 8, pp. 1112-1126, 2012.

[45] H. Satsu, Y. Hiura, K. Mochizuki, M. Hamada, and M. Shimizu, "Activation of pregnane X receptor and induction of MDR1 by dietary phytochemicals," Journal of Agricultural and Food Chemistry, vol. 56, no. 13, pp. 5366-5373, 2008.

[46] T. Aiba, M. Susa, S. Fukumori, and Y. Hashimoto, "The effects of culture conditions on CYP3A4 and MDR1 mRNA induction by $1 \alpha, 25$-dihydroxyvitamin $\mathrm{D}_{3}$ in human intestinal cell lines, Caco-2 and LS180," Drug Metabolism and Pharmacokinetics, vol. 20, no. 4, pp. 268-274, 2005. 